\title{
IVF/ICSI Outcomes of Euthyroid Infertile Women With TAI: Aspirin Plus Prednisone Treatment, Does It Matter?
}

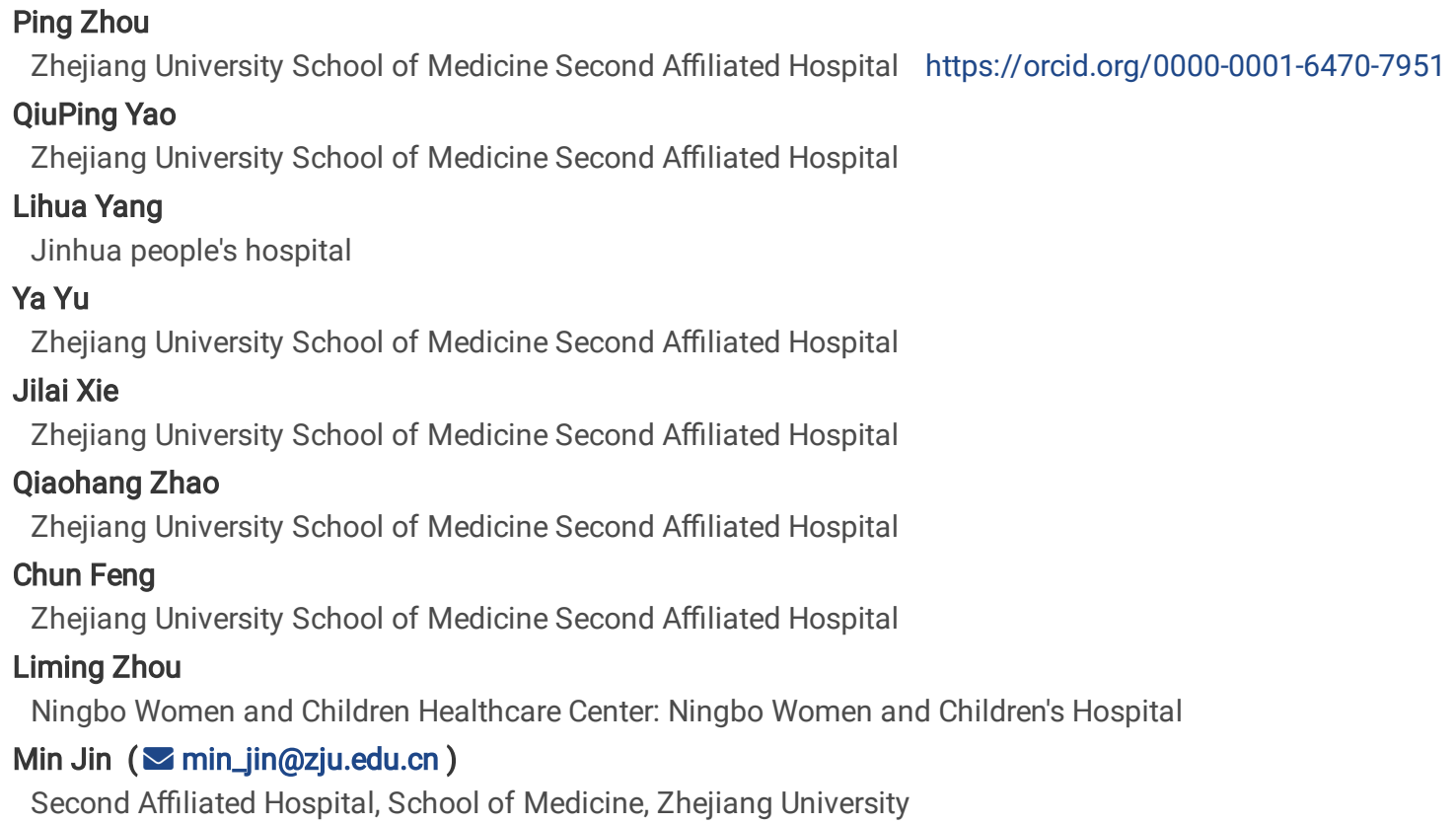

\section{Research}

Keywords: Thyroid autoimmunity, Euthyroidism, Aspirin, Prednisolone, Assisted reproductive technology

Posted Date: August 18th, 2021

DOI: https://doi.org/10.21203/rs.3.rs-805694/v1

License: (c) (i) This work is licensed under a Creative Commons Attribution 4.0 International License. Read Full License 


\section{Abstract \\ Objective}

Thyroid autoimmunity (TAI) per se has been demonstrated to be related to adverse pregnancy outcomes, including recurrent miscarriage and unexplained infertility. Although therapy of glucocorticoid to infertile remains controversial, aspirin combined with prednisone $(P+A)$ are used frequently in antithyroid antibodies (ATA) positive infertile women in clinical practice.

\section{Methods}

A multicenter retrospective study was performed in the Second Affiliated Hospital of Zhejiang University School of Medicine, Ningbo Women and Children's Hospital and People's Hospital of Jinhua. We recruited 494 euthyroid infertile women positive for anti-thyroperoxidase antibody (TPOAb) and/or thyroglobulin antibody (TgAb) with thyroid stimulating hormone $0.35-4.0 \mathrm{mlU} / \mathrm{L}$, who undergoing first in vitro fertilization and embryo transfer (IVF-ET) cycle during the period of 2017 to 2020. 346 women were ultimately recruited, including 187 patients receiving fresh embryo transfer and 159 patients receiving frozen-thawed embryo transfer. Among them, infertile 150 women were treated with prednisone $(10 \mathrm{mg} / \mathrm{d})$ and aspirin $(100 \mathrm{mg} / \mathrm{d})$, while the other 196 infertile women were untreated as control group. The treatment commenced on the day of embryo transfer and continued until the clinical pregnancy was determined by ultrasonography around 30 days after embryo transfer.

\section{Results}

Clinical pregnancy rate (CPR) of the first fresh embryo transfer cycle was $57.5 \%$ vs. $63.5 \%$ in control vs. in treated group $(P=0.414)$ and $C P R$ was $57.8 \%$ versus $61.8 \%$ in the two groups in the frozen-thawed embryo transfer cycle $(P=0.606)$. Additionally, the prevalence of delivering a live birth at the fresh embryo transfer was $49.6 \%$ in the non-treatment group and $47.3 \%$ in the $P+A$ treated group $(P=0.762)$. Cumulative $C P R$ was similar in the groups at the fresh embryo transfer (control vs treated group: $56.9 \% \mathrm{vs} 61.0 \%, \mathrm{P}=0.534$ ). By conducting logistic regression, combined treatment of $\mathrm{P}+\mathrm{A}$ appeared to have no influence on $\mathrm{CPR}$ or miscarriage rates (MR) at the first embryo transfer. Furthermore, the low but within the reference level of free triiodothyronine (FT3) was seen as a poor predictor of spontaneous abortion at the fresh embryo transfer.

\section{Conclusions}

To conclude, with regard to euthyroid women with TAl undergoing the first IVF-ET cycle, adjuvant treatment of P+A after the embryo transfer may be unnecessary irrespective of the fresh or frozen-thawed embryo transfer.

\section{Introduction}

In spite of numerous advances in the assisted reproductive technology (ART), such as controlled ovarian stimulation, assisted hatching and preimplantation genetic testing, implantation remains a long-standing and rate-limiting step in the IVF treatment[1]. To the best of our knowledge, to attain a successful implantation relies on the intricate collaboration of good-quality embryos with receptive human endometrium, both of which are indispensable[2-4]. Therefore, when good-quality embryos or even euploid embryos are prepared for the transfer, the endometrium may be responsible for the implantation failure[4, 5]. The major factors that establish uterine receptivity for implantation and further embryo development are progesterone, estrogens and the immunological system[6]. In addition, the reprogramming process of the maternal immune system from rejection to temporary tolerance towards the fetal (paternally derived) semi-allograft depends on the well-designed endocrineimmune interaction[7-9]. Generally speaking, normal female immune system usually induces tolerance toward the embryo, whereas the tolerance induction is incomplete in a hyperactive immune system, reducing fertility and increasing the risk of miscarriage[7]. Among the various studies investigating the immunological mechanisms, thyroid autoimmunity, as a predictor of generalized autoimmune disturbance, closely connected with recurrent embryo implantation failure, early pregnancy loss and adverse pregnancy outcomes[10-12]. Furthermore, several studies revealed that ATA did not affect embryo quality, but decreased clinical pregnancy rate, partly because of the impaired maternal immune[13]. In reality, for the purpose of dealing with reproductive challenges encountered by infertile woman who are positive for ATA and desire for pregnancy, prednisone $(P)$ for immunosuppression and aspirin $(A)$ as an antithrombotic agent are prescribed frequently and customarily in clinical practice.

As a therapeutic alternative, corticosteroid hormones in combination with aspirin probably pose a potential benefit on improving blood perfusion to the ovaries and endometrium, lowering the local inflammatory reaction to the transfer procedure, thus inducing a more favorable microenvironment for the transferred embryo[14, 15]. However, insufficient evidence existed to determine whether aspirin and prednisone therapy improve the likelihood of pregnancy following ART in thyroid Ab-positive euthyroid women. 
Aim of the study was to evaluate whether or not the treatment of prednisone in addition to aspirin was capable of improving pregnancy outcomes of the first IVF/ICSI cycle in euthyroid infertile women only with thyroid autoimmunity antibodies positive.

\section{Methods}

\subsection{Patients}

We conducted a multicenter retrospective study involving 494 infertile women who tested positive for TPOAb and/or TgAb and were being treated for infertility at the Second Affiliated Hospital of Zhejiang University School of Medicine, Ningbo Women and Children's Hospital and People's Hospital of Jinhua from October 2017 to July 2020. Both TPOAb and TgAb in all the subjects were measured before ART procedure, and their thyroid stimulating hormone (TSH) level ranged from 0.35-4.0mIU/L and also, they all underwent first embryo transfer without previous IVF history. That is to say, we screened and involved only first-time ART users and analyzed only first embryo transfer (fresh or frozen-thawed embryo transfer) and first cycle. Inclusion criteria were age of less than 40 years, regular (21-35days) spontaneous menstrual cycle, normal uterine cavity, presence of both ovaries, and normal ovarian reserve as defined by basic follicle stimulating hormone(bFSH) $<10 \mathrm{IU} / \mathrm{L}$ and antral follicle count (AFC) no less than 5.

Women with known autoimmune diseases or clinical presentations of autoimmune disorders including systemic lupus erythematosus (SLE), antiphospholipid syndrome (APS) $(n=2)$, in whom thyroid function test were not normal $(n=38)$, who were diagnosed with diseases affecting the uterine cavity $(n=12)$, and those infertility caused by severe oligoasthenospermia and azoospermatism $(n=16)$ were excluded. Equally, 8 women or their partners with aberrant chromosome karyotype particularly significant parental balanced translocations or Turner mosaicism were ruled out. One woman was excluded due to medical history of insulin-dependent diabetes mellitus (DM), 7 women due to no mature oocyte to retrieve and 64 women on account of receiving no embryo transfer for various reasons.

Of the remaining ATA (+) women, 187 women achieved fresh embryo transfer and 159 women fulfilled frozen-thawed embryo transfer, 150 (43.4\%) patients received P + A treatment during ART(Fig. 1). The study was reviewed and approved by the Ethics Committee of the Second Affiliated Hospital of Zhejiang University School of Medicine, Ningbo Women and Children's Hospital and People's Hospital of Jinhua.

\subsection{Laboratory assays}

Women's serum samples were analyzed by the standard third-generation electrochemiluminescence (ECL) immunoassay (CobasElesys 601, Roche) in the three reproductive centers. Thyroid autoimmunity (TAl) was defined as the presence of serum antibodies directed against TPO and/or TG. The reference range was $0-5.61 \mathrm{IU} / \mathrm{mL}$ for TPOAb and $<4.11 \mathrm{IU} / \mathrm{mL}$ for TgAb. TPOAb titers of more than $5.61 \mathrm{IU} / \mathrm{mL}$ and/or TgAb values exceeding $4.11 \mathrm{IU} / \mathrm{mL}$ were considered ATA-positive. Women were diagnosed with euthyroidism when serum levels of TSH were within the reference of $0.35-4.0 \mathrm{mIU} / \mathrm{L}$ and none of the free thyroxine (FT4) or triiodothyronine (FT3) was outside their reference ranges. The reference values were $0.7-1.48 \mathrm{ng} / \mathrm{dL}$ for FT4 and $1.71-3.71 \mathrm{pg} / \mathrm{mL}$ for FT3. These reference values were given by the company producing these assay kits.

\subsection{ART procedure and collection of clinical information}

All patients underwent ovulation induction with recombinant follicle-stimulating hormone (rFSH) (Gonal F; Serono, Switzerland) or human menopausal gonadotropin (HMG) (Livzon, China) to obtain a cohort of mature oocytes at the time of oocyte retrieval. Pituitary inhibition was achieved by a gonadotropin-releasing hormone (GnRH) analog (Decapeptyl; Ferring, Switzerland) or GnRH antagonist (Centrotide; Serono, Germany). The doses of these drugs were adjusted according to the women's age and the number of antral follicles and day three serum FSH values. Cycle monitoring was carried out using transvaginal sonography plus laboratory assays. As soon as a minimal of three leading follicles reaching 17 to $18 \mathrm{~mm}$ paired with appropriate serum E2 levels, 5000-10,000 IU of human chorionic gonadotropin (hCG) (Livzon, China) was administered. Therefore, by virtue of the guiding of transvaginal ultrasound, cumulus oocyte complexes (COCs) were aspirated 36 to 38 hours after hCG injection. Subsequently, whether using conventional IVF or ICSI was relied on the semen condition and clinical indication. The previous history of obtaining poor-quality oocytes, recurrent fertilization failure with IVF technique and high titers of anti-sperm antibodies favored ICSI. Under the condition of tubal factor or unexplained infertility, and ovulation failure with all possible conventional methods, the IVF procedure was employed.[16]. On day 2 and 3 after oocyte collection, embryos were assessed and scored according to the number and size (even or uneven) of blastomeres, fragmentation, and multinucleation. Embryos were transferred on the third, fifth or sixth day of culture according to the age of the patient and embryo quality. All patients were transferred of the best quality embryos. According to the ART regulation published in 2018 , the total number of embryos transferred per cycle shall not exceed three, including no more than two embryos for women under the age of 35 during the first cycle of assisted reproduction. In the frozen-thawed embryo transfer cycle, hormone replacement treatment with estradiol administered orally ( $6 \mathrm{mg} /$ day) from the third day of the target cycle or natural cycle was adopted for endometrial preparation. An ultrasound examination was performed to measure and record endometrial thickness as the maximum distance $(\mathrm{mm})$ between the myometrium and endometrial surface. A thickness of $\geq 7.5 \mathrm{~mm}$ was considered satisfactory for initiating progesterone supplementation. Luteal phase support was added in the form of micronized progesterone capsules and oral dydrogesterone starting from the day of oocyte collection in the fresh embryo transfer 
cycle and continued until the day of the pregnancy test. When the patient was pregnant, the supplement was continued during the first pregnancy trimester. Fourteen days after ET, serum hCG was assessed for the confirmation of biochemical pregnancy and clinical pregnancy was determined by ultrasonography to visualize an intrauterine gestational sac, which was performed 5weeks after ET. The following clinical data including women's age, body mass index (BMI), duration of infertility, previous history of miscarriage, bFSH, anti-Mullerian hormone (AMH), antral follicle count (AFC) were recorded and analyzed. Laboratory parameters and pregnancy outcomes were also documented: total gonadotropin (Gn) doses, days of Gn treatment, E2 levels on hCG day, endometrial thicknesses on hCG day and embryo transfer day, oocytes retrieved, fertilization rate, number of embryos for transferring, implantation rate of cleavage and blastocyst stage embryos, pregnancy rate (PR), clinical pregnancy rate (CPR), miscarriage rate (MR), live birth rate (LBR) and cumulative rate.

\subsection{Adjuvant medical treatments}

Overall, a total of 346 euthyroid infertile women with TAI were divided into two groups, the control group involving 196 patients as well as prednisone (Xianju pharmaceutical factory, China) plus aspirin (Bayer, Germany) $(P+A)$ treated group consisting of 150 women. As illustrated in Fig. 1, 187 women acquired fresh embryo transfer and of them 74(39.6\%) received $P+A$ adjuvant medicine. Among 159 frozen-thawed embryo transfer, 76(47.8\%) were supplied with prednisone plus aspirin. In the treatment group, a daily dose of 100mg orally administered aspirin(A) and $10 \mathrm{mg}$ prednisone $(\mathrm{P})$ started from the day of ET and continued until the time of hCG test. The positive hCG test indicated ceaseless medication and drug stopped at the time when successfully clinical pregnancy was established. Treatment was also discontinued if persistent hCG decline occurred.

\subsection{Outcome measures}

Primary outcome was clinical pregnancy rate (CPR) after the first embryo transfer. Secondary outcomes were implantation rate of cleavage stage embryos, miscarriage rate (MR) and live birth rate (LBR) after the first embryo transfer. Besides, cumulative pregnancy rate, clinical pregnancy rate as well as live birth rate were also reported.

Pregnancy rate was the percentage of transfers with positive serum level of beta-hCG ( $\geq 5 \mathrm{mlU} / \mathrm{mL}$ ). Clinical pregnancy was defined as the existence of a viable embryo within an intrauterine gestational sac. Spontaneous abortion rate was defined as the ratio between the number of pregnancy loss after sonographic visualization of an intrauterine gestational sac and the number of clinical pregnancies. Recurrent miscarriage (RM) is defined by the loss of two or more clinical pregnancies. Implantation rate was calculated as the number of sacs with fetal heart beat divided by the total number of embryos transferred. Live birth rate was the percentage of transfers resulting in a live birth. Cumulative rate was calculated as soon as the first IVF cycle was completed or patients without delivering a live birth were followed up to 1 years after the first embryo transfer when the first IVF cycle was not completed. A complete cycle was characterized as all transfer cycles in an IVF cycle started with oocyte stimulation, ended with live birth or no available embryos or abandonment.

\subsection{Statistics}

Data analysis was performed using the Statistics Package for Social Sciences (SPSS 24.0). First, a Kolmogorov-Smirnov test was applied to both groups and variables to evaluate whether the distribution was symmetrical or not. Continuous data were expressed as median (25th-75th) when not normally distributed, and as mean \pm SD for normally distributed data. Categorical data were calculated as numbers (percentage) of cases. Comparisons of quantitative data were analyzed by the Mann-Whitney $U$ test or independent $T$ test on the basis of distribution status and Chi-square or two-sided Fisher's exact test was deployed in categorical data.

For the logistic regression analysis, the independent variables were age and FT3 levels in the whole range. CPR and MR were considered as dependent outcomes.

The significance level of alpha was defined as 0.05 . And a value of $p<0.05$ was considered statistically significant.

\section{Results}

\subsection{Clinical characteristics}

Characteristics of women with positive antithyroid antibodies were shown in Table 1. Obviously, the clinical descriptive characteristics were broadly comparable between $\mathrm{P}+\mathrm{A}$ treated group and non-treated group, which consisted of age, BMI, number of previous miscarriages, duration of infertility, the proportion of primary infertility, bFSH, AMH, AFC, TSH, FT4, the ratio of only TPOAb positivity, only TgAb positivity, or TPOAb and $\mathrm{TgAb}$ positivity. Furthermore, the cause of infertility was comparable between those groups (Supplemental Table SI). Firstly, we turned to the fresh embryo transfer cycles. In women of treated group, the median age of the women was 31.0(29.0-35.0) years old and the majority was within the range of 31-37 years old, the data similar to the control group. For these two groups, the overweight and obesity patients accounted for $22.0 \%$ (control group) and $22.3 \%(P+A$ group), respectively $(P=0.336)$. The prevalence of women with recurrent abortion was $20.3 \%$ in the $P$ 
+ A treated group, with a slightly and nonsignificant higher percentage compared with that in counterpart $(20.3 \% \mathrm{vs} 18.6 \%, \mathrm{P}=0.775)$. Besides, the incidence of women with primary infertility was $40.5 \%$ in treated group and comparable between study groups (40.5\%vs $44.2 \%, \mathrm{P}=0.616)$. Patients were homogenous for basal hormone measurements and antral follicle count, indicating a similar ovarian reserve. The value of FT3 in the $P+A$ treated group was $2.90 \pm 0.39 \mathrm{pg} / \mathrm{mL}$, significantly lower than that of ATA-positive untreated subjects $(3.05 \pm 0.44, P=0.017)$. Of 74 treated women investigated, $9.5 \%(n=7)$ had only TPOAb positivity, $37.8 \%(n=28)$ had only $\operatorname{TgAb}$ positivity and the remaining $52.7 \%(n=39)$ had both TPOAb and TgAb positivity. Secondly, as to frozen-thawed embryo transfer cycles, women with a history of more than 2 pregnancy loss was $10(13.2 \%)$ in treated group and $7(8.4 \%)$ for control group $(P=0.336)$.

\subsection{Cycle characteristics and embryological data}

No significance was observed in the ratio of GnRHant/GnRHa, days of ovarian stimulation, total Gn doses, E2 levels on hCG day, endometrial thicknesses on hCG day, number of oocytes retrieved and the type of ART used between two groups at both fresh and frozen embryo transfer cycles (Table 2). With regard to fresh embryo transfer cycles, in the treated group, GnRH agonists were used more to initiate the ART (68.9\%) and the median dosage of gonadotropins used to stimulate the ovary was 2250.0(1762.5-2925.0) IU (comparable between groups). The median(25th-75th) level of E2 on hCG day and oocytes retrieved were $2287.10 \pm 865.47 \mathrm{pg} / \mathrm{mL}$ and $10.0(6.0-15.0)$, and the numbers were similar when compared with those in the women without treatment $(2246.77 \pm 980.18 \mathrm{pg} / \mathrm{mL}, \mathrm{P}=0.547 ; 9.0(5.0-12.0), P=0.053)$. The prevalence of IVF applied as the type of ART was $94.6 \%$ in treated women and comparable between study groups. The fertilization rate (FR) in women with TAl treated with $\mathrm{P}+\mathrm{A}$ versus non-treatment was comparable ( $80.4 \%$ vs. $82.6 \% ; \mathrm{p}=0.217)$. Of cured women, the cleavage rate $(\mathrm{CR})$ was $93.5 \%$ and available embryo rate was $56.2 \%$, the latter was nonsignificantly inferior to $61.2 \%$ in the control group $(P=0.058)$. For the rest frozen-thawed embryo transfers, all results were comparable between groups.

\subsection{Reproductive outcomes}

When it came to fresh embryo transfer, we prudently observed and documented the following results (Table 3). An apparent high percentage of cleavage stage embryos were transferred in the treated group, compared with blastocyst stage ( $97.3 \%$ versus $2.7 \%$, respectively). Similar feature was observed in the control group. The mean (SD) number of embryo transferred was $1.93 \pm 0.25$ in the treated group, comparable with that of the control group $(1.88 \pm 0.33, P=0.214)$. Implantation rate of cleavage stage embryos was calculated as $44.7 \%$, with a slightly (nonsignificant) increased chance of women with medication administration than that of women without medication (44.7\% vs. 40.2\%; P $=0.407)$. As for pregnancy rate, treated women carried similar pregnancy rate in comparation with the control group $(64.9 \%$ vs. $63.7 \%$; $p=0.873)$ and a higher but nonsignificant prevalence of clinical pregnancy $(63.5 \%$ vs. $57.5 \%$; $=0.414)$. Nonsignificantly, more miscarriages took place in the treated group than the control group at the first attempt ( $25.5 \%$ versus $13.8 \% \mathrm{P}=0.118)$. The prevalence of the treated women with live birth was $47.3 \%$ versus $49.6 \%$ of the control group $(P=0.762)$ and cumulative live birth rate was $46.0 \%$ versus $47.7 \%(P=0.799)$. When talking about frozen embryo transfer, the outcome was analogous to fresh embryo transfer result. The endometrial thickness on embryo transfer day was in accordance at two study groups (9.1(8.5-11.0) $\mathrm{mm}$ vs $9.1(8.5-11.0) \mathrm{mm}, \mathrm{P}=0.984)$. Notably, an elevated but nonsignificant prevalence of cleavage stage embryo implantation and clinical pregnancy occurred in the treated women in contrast with the untreated women (45.5\% vs $39.7 \%, P=0.341 ; 61.8 \%$ vs $57.8 \%, P=0.606$ ). Besides, the incidence of the treated women with miscarriage was $27.7 \%$ versus $18.8 \%$ of the control group $(P=0.303)$. Not only at the first frozen embryo transfer, but also under the circumstance of the cumulative incidence rate, the treated group bore similar likely to delivering a live birth contrary to what was observed in the control group (44.7\% vs $47.0 \%, \mathrm{P}=0.776 ; 43.0 \%$ vs $45.7 \%, P=0.714)$.

\subsection{Logistic regression analysis}

Since there was a significant difference in FT3 at the fresh embryo transfer cycle between women with or without P + A treatment, we performed a multiple logistic regression analysis and also took age, the clinically relevant variable, into account (Table 4 .). In women transferred with fresh embryos, after adjusting for age and additional treatment, significantly, FT3 within the normal reference appeared to have a negative relationship with miscarriage rate (odds ratio [OR] 0.248 [95\% confidence interval, $\mathrm{Cl} 0.063-0.984$ ], $\mathrm{P}=0.047$ ). Furthermore, $\mathrm{P}$ plus $\mathrm{A}$ treatment was presented to exert no influence on miscarriage rate or clinical pregnancy rate.

\subsection{Recurrent pregnancy loss and IVF outcome}

Baseline demographics and clinical characteristics were comparable between groups (Supplemental Table SII). Based on our analysis, there was an absence of association between treatment with $\mathrm{P}+\mathrm{A}$ and subsequent pregnancy outcomes in women suffering for unexplained recurrent pregnancy loss (RPL) who had autoimmune thyroid disease (Supplemental Table SIII). However, the study was not adequately powered for this outcome on account of its small sample size. It definitely required caution to illustrate and further investigations, preferably randomized controlled trials, to assess the value of the additional treatment in RPL women with thyroid autoimmunity.

\subsection{Comparison of IVF outcomes of continuous embryo transfers}

Page 5/18 
The comparison of IVF outcomes of continuous embryo transfers in women receiving nothing at the first embryo transfer but obtaining therapy at the additional frozen embryo transfers was depicted in Supplemental Table SIV. In other words, this part was before-after study in the same patients. As shown in the Supplemental Table SV, the presence of prednisone and aspirin seemed to be not of benefit to final reproductive outcomes. Nevertheless, there existed obvious shortcomings of limited eligible evidence, discrepant ratio of cleavage stage embryo to blastocyst stage embryo and various type of embryos transferred, fresh or frozen-thawed, implying an inevitably questionable conclusion.

\section{Discussion}

The correlation between antithyroid antibodies, fecundity and pregnancy outcome is quite debatable and conflicting. Previously, meta-analysis of 4 prospective studies that included 1098 subfertile women undergoing IVF noted a significant two fold higher risk of miscarriage of subfertile euthyroid women with TAl compared with a counterpart without TAI[17]. Among those four prospective studies, three of them only measured TPO-Ab, one study recruited participants with unexplained infertility and no history of miscarriage, subfertile women with various etiology and normal thyroid function was reported in another two prospective investigations and the last one specifically excluded women with a history of miscarriage. Under the circumstances of different ART/IVF protocols employed, dissimilar underlying etiologies contributing to infertility and changeable cut-off values concerning euthyroidism and subclinical hypothyroidism, the 2017 American Thyroid Association (ATA) pregnancy guidelines was not able to come to a definite conclusion on the link between thyroid autoimmunity and ART outcomes. What's more, levothyroxine treatment was recommended for subclinical hypothyroidism, defined as a TSH $>2.5$ mIU/L, and considered for euthyroid infertile women with thyroid autoimmunity when they attempted to conceive by virtue of assisted reproductive technologies in the 2017 ATA guidelines after weighing the pros and cons of levothyroxine supplement[18].

However, in the past few years following the publication of the 2017 ATA guidelines, two large randomized controlled trials(RCT) assessing the value of levothyroxine on pregnancy outcomes in euthyroid TPO-Ab positive women reported that the use of levothyroxine was not associated with improvements on miscarriage and live birth rate[19,20]. Though there existed several limitations involving fixed levothyroxine doses, undetermined TSH values during early trimester of pregnancy following medicine supplement, uncertain population compliance and the exclusion of women with recurrent miscarriages or positive for other autoimmune antibodies, the large-sample RCT results were essential and provoking on levothyroxine effectiveness in the specific euthyroid women with thyroid autoimmunity[21]. Furthermore, a recent meta-analysis of six RCTs demonstrated that levothyroxine had no capacity to improve clinical pregnancy outcomes among women positive for thyroid peroxidase antibody. As a matter of fact, of the meta-analysis based on high- to moderate-quality evidence, two trials underwent ART, two studies used fixed levothyroxine doses and one investigation enrolled euthyroid or subclinical women[22]. Thus, further large-scale high-quality investigations on specific population are still urgently needed.

On account of decreased effectiveness of levothyroxine and generalized autoimmune imbalance resulted from thyroid autoimmunity, we retrospectively explored the power of aspirin plus prednisone treatment on euthyroid women with TAI undergoing their first IVF/ICSI procedure. Markedly, there exists a robust, dynamic and responsive immune system for a successful pregnancy. Pregnancy begins in a pro-inflammatory stage allowing implantation and placentation, then shifts to an anti-inflammatory environment which is pivotal for fetal growth, and finally come back to a pro-inflammatory stage available to labor and delivery. A pro-inflammatory process is initiated in the embryo implantation and trophoblast invasion to better promote cell clearance, angiogenesis, cell growth and tolerance, as the pro-inflammatory procedure is characterized by the presence of angiogenic factors, growth and survival factors, and cytokines and chemokines[23]. Following implantation, the female immune system usually induces tolerance towards the embryo, whereas tolerance induction is incomplete in a hyperactive immune system. Subfertile women with autoimmune thyroid disease usually expressed increased level of INFy from pro-inflammatory Th1 immune cell and reduced secretion of IL-4 and IL-10 from Th2 immune cell compared to controls with no anti-thyroid antibodies, suggesting that the excessive activated pro-inflammatory Th1 cell hampered the subsequent successful pregnancy[24]. Moreover, pinopodes, the spherical protrusions of the epithelial plasma membrane into the lumen, are characterized as classic morphological biomarkers of receptive endometrium favoring implantation. Recently and firstly, a euthyroid Hashimoto's thyroiditis (HT) mice model was established and explored the correlation of HT and endometrial receptivity defects, indicating that HT alone inhibited luminal epithelium development, retarded the formation and development of pinopodes, decreased expression of receptivity markers, thereby inducing a nonreceptive endometrial milieu and leading to implantation failure[25]. Prednisone, a type of glucocorticoid, is readily absorbed from the gastrointestinal tract and used primarily for its antiinflammatory effects in many system disorders[26]. A substantial amount of trials revealed that low doses of corticosteroids (10 mg/day) had improved the IVF pregnancy outcome in women experiencing immunological infertility and recurrent miscarriages, even with a prior history of 19 consecutive miscarriages[27-30]. Moreover, by virtue of cleavage stage mouse embryos exposing to 3 and $30 \mu \mathrm{M}$ concentrations of prednisolone(PRDL) in vitro to mimic the possible clinical scenario and to assess the embryonic response to direct PRDL exposure, a recent animal study revealed that exposure to $30 \mu \mathrm{M}$ PRDL delayed the embryonic progression, decreased hatching potential and increased apoptosis in blastocysts, and yet, $3 \mu \mathrm{M}$ PRDL exposure increased inner cell mass (ICM) proliferation ability which was incorporated to predict the implantation potential[31]. It was worth mentioning that $3 \mu \mathrm{M}$ was close to the therapeutic dose and $30 \mu \mathrm{M}$ to reflect the ten-times higher than the initial level. Experimental evidences in animal models implied that glucocorticoids at higher concentrations could negatively affect oocyte maturation and early embryogenesis. The therapeutic dose of PRDL had the capacity to reduce post-implantation demise, possibly due to its 
stimulus on choriocarcinoma cell lines. Similarly, the latest trial to investigate the role of prednisolone on decidualization and decidualtrophoblast interactions reported that prednisolone treatment enhanced trophoblast outgrowth, elevated trophoblast mRNA expression of cell motility gene PLCG1, altered decidual-trophoblast interactions and yet the clinical consequences of these changes were unknown[32]. Thus, there remains a great need for further research on this topic. On the other side, with the capacity to decrease blood viscosity and increase blood flow, which is secondary to the inhibition of cyclooxygenase- 1 and decreased production of thromboxane-2, low dose of aspirin plays an essential role in improving uterine and ovarian blood flow, enhancing embryo implantation and sustaining early pregnancy. Besides, daily lowdose aspirin use is considerably safe as it did not contribute to any changes to menstrual cycle, follicular phase, or luteal phase length or hormone levels across the menstrual cycle[33]. The adjuvant treatment of aspirin in combination with prednisone is recommended to patients with autoantibodies undergoing IVF as its benefits are demonstrated in several investigations[27, 28, 34]. However, these trials are published from a long time ago and don't reveal the efficacy of medicine on infertile women who present positive only for antithyroid antibodies.

In our study, we applied ranges of $<31$ years, 31-37 years, and > 37 years according to the physiological understanding of natural fertility, whose initial decline began at 31 years and the critical age of 37 years recorded as the pivotal age for success rates in treatment programs[35, 36]. Notably, the rough distribution of age was comparable and thus reduced the potential confounding risk of age, as advanced age predisposed to induce increased chance of de novo chromosomal aberrations in oocytes, and, in turn, in the embryo[11, 37, 38]. With regard to ovarian reserve, age, $\mathrm{AMH}, \mathrm{AFC}$ and bFSH were comparable between women administrated with medicine or not at both fresh and frozen embryo transfer cycles. Additionally, significant parental chromosome abnormality, severe oligoasthenospermia and azoospermatism were definitely excluded in our study as the rate of chromosomal anomaly was $0.24 \%$ in normal semen group, $4.7 \%$ in moderate-to-severe oligoasthenospermia group and $9.59 \%$ in azoospermia group[39]. The consistency between two groups provided confidence for us to come to the final conclusion as $30-50 \%$ of implantation failures can be attributed to poor embryo quality and the embryo quality is determined by a number of parameters primarily of the women's age, ovarian reserve, the underlying causes of infertility and sperm quality. In addition, decreased endometrial receptivity is thought to account for similarly two thirds of these failures[5]. Typically, endometrium is the direct or indirect target of antithyroid antibodies, prednisone and aspirin.

In the context of the unclear and indefinite efficacy of both antibodies, we recorded and analyzed the proportion of positive isolated TPOAb, positive isolated TgAb, and double positive TPOAb and TgAb in our study and no significant difference was observed. Moreover, in our study, euthyroidism was defined as the reference value of $0.35-4.0 \mathrm{mIU} / \mathrm{L}$ for the TSH and the value was comparable between two groups. The borderline of euthyroid and subclinical hypothyroidism is changeable over time. Nowadays, the association between elevated maternal TSH concentrations and pregnancy-specific complications appears to be more pronounced when adopting the the cut-off point of $4.0 \mathrm{mIU} / \mathrm{L}$, or a population-based reference value than the level of $2.5 \mathrm{mIU} / \mathrm{L}[40]$. And newer guidelines suggested that an upper limit of $4.0 \mathrm{mIU} / \mathrm{L}$ should be considered diagnostic compared with the previous guideline of $2.5 \mathrm{mlU} / \mathrm{L}[18]$. Based on the borderline of $4.0 \mathrm{mIU} / \mathrm{L}$ for the TSH and 2017 ATA recommendations, levothyroxine supplement was not included in our study.

Interestingly, we observed no association between prednisone plus aspirin treatment and reproductive outcomes including CPR, MR and LBR at the first embryo transfer regardless of fresh or frozen embryo transfer. Selected and assessed infertile women owned normal thyroid test and no autoimmune antibodies except anti-thyroid antibodies. This finding had not been replicated in other literature and should be interpreted with caution. In 2009, Alberto Revelli et al performed a retrospective study of 329 euthyroid women who were positive for TPOAb, TgAb, or both. The medication was prednisolone $(10 \mathrm{mg} / \mathrm{d})$ and aspirin $(100 \mathrm{mg} / \mathrm{d})$ from the day of stimulation to 10 weeks of gestational age, and during that period, $\mathrm{P}$ was increased to $30 \mathrm{mg} / \mathrm{d}$ for 5 days starting from the day of ET. Such a medication approach was acknowledged as of value on pregnancy and implantation rates in contrast with untreated ATA + patients[34].The timing of medication in our study commenced on the day of embryo transfer and lasted for 2-6weeks, mainly focusing on fascinating the implantation micro-immune environment. In a prospective casecontrol study including 233 consecutive patients, dexamethasone $(0.5 \mathrm{mg} / \mathrm{d})$ and acetylsalicylic acid(100 mg/d) starting from the day of embryo transfer and continuing until the end of the 12th week of gestation increased the pregnancy rate and implantation rate when compared with the control group[42].But it was noteworthy that the inclusion of this prospective study was inherited and acquired thrombophilia, compound heterozygous polymorphisms, positive anti-nuclear and anti-thyroglobulin antibodies, the strong indication for steroid hormone and anticoagulant drug[42]. Coincidentally, its inclusion standard was exactly in line with the exclusion criteria in our study, which largely explained the conflicting results. Thus, the effective value of treatment may be not obvious in women with unaffected thyroid function and only thyroid antibodies when compared with those with multiple types of autoantibodies or the history of RPL.

When talking about the mixed correlation between TAl and infertility, a recent review published in 2020 may help us to have a better understanding of its relevance. By summarizing and analyzing the latest studies since the 2017 guidelines, the review documented that anti-TPO Abs were associated with infertility in subsets of women mainly with unexplained infertility or polycystic ovarian syndrome (PCOS), but not all women[21]. Such a conclusion was primarily dependent on a secondary analysis of data from two multicenter RCTs involving 1650 euthyroid infertile women either with unexplained infertility or PCOS[41]. The weak correlation of TAl and IVF reproductive outcomes of general infertile population possibly partially explained the negative results of our study. Furthermore, a 2020 meta-analysis of seventeen studies pinpointed a statistically significant association between RPL and TAl (odds ratio 1.94; 95\% Cl, 1.43-2.64) and the statistical significance and magnitude of 
the results remained unchanged following sensitivity analyses[43], similar to the finding of our previous investigation[44]. As for euthyroid infertile women with unexplained infertility, PCOS or RPL, little evidence existed concerning the effect of replacement therapy of A plus P in those specific women. Besides, owning to the paucity of a great number of subjects, stratified research is usually not likely to fulfill at the subgroup level. However, based on the fact that P plus A treatment did play a positive role on improving adverse IVF reproductive outcomes in women with positive antinuclear antibodies[45], with unexplained RPL[46] and with other immune-related antibodies[15]. Combined treatment is likely to exert great influence on euthyroid infertile women with TAl and unexplained infertility or RPL, though it still requires prospective large-sample trials to justify its potency.

Additionally, in our study, there existed a phenomenon that no matter what type of embryo transferred, a higher but not significant incidence of abortion occurred in the treated group. As illustrated above, the value of FT3 in the P + A treated group was $2.90 \pm 0.39 \mathrm{pg} / \mathrm{mL}$, significantly lower than that of ATA-positive untreated subjects $(\mathrm{P}=0.017)$. Multivariable logistic regression demonstrated the negative role of FT3 played on the incidence of fetus loss at the first fresh embryo transfer. The demonstration was buttressed by a preliminary observational study, which reported that low serum FT3 level compromised the beneficial effect of levothyroxine substitution in women with Hashimoto thyroiditis[47]. It is widely acknowledged that thyroid hormone transporters, receptors and their associated proteins are expressed in the ovary, the early embryo, endometrium, uterus and placenta[7]. Thus, optimal value of T3 is crucial for ovulation and folliculogenesis as T3 in combination with FSH appears to enhance granulosa cell proliferation and inhibit granulosa cell apoptosis via the PI3K/Akt pathway[7, 16]. Simultaneously, the expression of these proteins in the endometrium is changeable throughout the various phases of the menstrual cycle[48]. It's documented that receptive endometrium is accompanied with strengthened expression of thyroid hormone(TH) receptors in normal women[49], whereas weakened expression of proteins concerning thyroid hormone in the uterus is observed at the day of implantation in hypothyroid pregnant rats[50]. By means of the binding of TH receptors on the placenta and endometrium, as well as regulating the invasive potential of extravillous trophoblasts, thyroid hormone is capable to affect implantation and early fetal development[7]. To conclude, the evidence and statement above seemingly suggest the provision of additional levothyroxine supplement in euthyroid infertile women with low but in the normal reference range of FT3. One potential pathogenesis model with regard to the link between thyroid autoimmunity and fertility may offer us a new perspective[21].At early stages of autoimmunity, the main undesirable impact is through a hostile immune environment at the level of the ovary, with TPO as the direct antigen. At this stage, the thyroid hormone response is intact and the levothyroxine treatment is inefficient. As thyroid autoimmunity progresses, an impaired thyroid response to hCG stimulation appears and unable to meet the excess thyroid hormone demand under the condition of pregnancy. In that situation, treatment with thyroid hormone will be beneficial[21]. On the basis of such a new model, to distinguish the different stage is the key to efficient treatment.

Although progress has been made in some areas of the autoimmune disorders, little is known about the comprehensive understanding of the underling mechanism of autoimmune antibodies on reproductive outcome, leading to a barrier to a deeper search of effective treatments. Organs-on-a-chip, claimed as advanced in vitro models of multicellular tissue complexes or functional organ units, may help illuminate the possible intricate connection. Exploiting organ-on-a-chip approaches to modeling decidualization, implantation and placentation, they are capable of in-depth investigating the invasive and remodeling behavior of extravillous trophoblast cells, the procedure crucial of establishing the uteroplacental circulation that provides vascular supply to the growing fetus[51]. Further to that, interaction of antibodies and endometrium, changeable expression of immunological factors as well as glucocorticoid acting point are all standing a chance of being explored.

To conclude, according to the reality of routine thyroid screening, a large number of euthyroid women who test positive for antithyroid antibodies are discovered. Among them, patients underwent the first IVF cycle without the history of recurrent miscarriages or unexplained infertility are not recommended for the combined treatment of prednisone and aspirin. As a whole, there were several advantages in our study. Firstly, by means of establishing strict inclusion and exclusion criteria, we controlled for the possible confounding factor of other autoantibodies and several severe detrimental elements of spontaneous miscarriages to minimize, as much as possible, any patient-related variation in order to concentrate on the effects of aspirin in combination with prednisone on isolated euthyroid infertile women with TAl. Secondly, we only included first-time ART users and analyzed only first cycle ART outcomes to investigate homogeneous good-prognosis population and provide relevant suggestions for targeted subjects. Additionally, our study also had some limitations. Firstly, the current study was inevitably limited by its retrospective nature. Secondly, given the variation of TPOAb and TH concentrations in the context of pregnancy, measurement of longitudinal thyroid parameters during pregnancy was appreciable and yet we did not record the change[52]. While P+A supplement did not improve live birth rate or pregnancy rate in euthyroid TAl women at the first embryo transfer, the potential benefits of $P+A$ supplementation during pregnancy could not be ruled out. Additional randomized clinical trial is required to determine whether $\mathrm{P}+\mathrm{A}$ yield different results on women who test positive for antithyroid antibodies with recurrent implantation failure or with unexplained infertility. Similarly, it is possible that a higher risk population with increased recurrent pregnancy loss might yield different results.

\section{Conclusion}

To conclude, according to the reality of routine thyroid screening, a large number of euthyroid women who test positive for antithyroid antibodies are discovered. Among them, patients underwent the first IVF cycle without the history of recurrent miscarriages or unexplained infertility are not

Page $8 / 18$ 
recommended for the combined treatment of prednisone and aspirin.

\section{List Of Abbreviations}




\begin{tabular}{|c|c|}
\hline thyroid autoimmunity & TAl \\
\hline antithyroid antibody & ATA \\
\hline thyroperoxidase antibody & TPOAb \\
\hline thyroglobulin antibody & $\operatorname{TgAb}$ \\
\hline in vitro fertilization and embryo transfer & IVF-ET \\
\hline clinical pregnancy rate & CPR \\
\hline miscarriage rate & MR \\
\hline free triiodothyronine & FT3 \\
\hline prednisone and aspirin & $P+A$ \\
\hline assisted reproductive technology & ART \\
\hline thyroid stimulating hormone & TSH \\
\hline basic follicle stimulating hormone & bFSH \\
\hline antral follicle count & AFC \\
\hline systemic lupus erythematosus & SLE \\
\hline antiphospholipid syndrome & APS \\
\hline diabetes mellitus & DM \\
\hline electrochemiluminescence & ECL \\
\hline free thyroxine & FT4 \\
\hline recombinant follicle-stimulating hormone & rFSH \\
\hline human menopausal gonadotropin & HMG \\
\hline gonadotropin-releasing hormone & $\mathrm{GnRH}$ \\
\hline human chorionic gonadotropin & hCG \\
\hline cumulus oocyte complexes & cocs \\
\hline body mass index & $\mathrm{BMI}$ \\
\hline anti-Mullerian hormone & $\mathrm{AMH}$ \\
\hline antral follicle count & AFC \\
\hline gonadotropin & $\mathrm{Gn}$ \\
\hline pregnancy rate & PR \\
\hline live birth rate & LBR \\
\hline Recurrent miscarriage & $\mathrm{RM}$ \\
\hline Statistics Package for Social Sciences & SPSS \\
\hline fertilization rate & $\mathrm{FR}$ \\
\hline cleavage rate & $\mathrm{CR}$ \\
\hline recurrent pregnancy loss & RPL \\
\hline American Thyroid Association & ATA \\
\hline randomized controlled trial & RCT \\
\hline Hashimoto's thyroiditis & HT \\
\hline prednisolone & PRDL \\
\hline inner cell mass & $\mathrm{ICM}$ \\
\hline polycystic ovarian syndrome & PCOS \\
\hline
\end{tabular}

Page 10/18 


\begin{tabular}{|lc|}
\hline thyroid autoimmunity & TAI \\
\hline thyroid hormone & TH \\
\hline
\end{tabular}

\section{Declarations}

\section{Acknowledgement}

The authors thank the staff of Reproductive Medicine Center of Second Affiliated Hospital of Zhejiang University School of Medicine, Ningbo Women and Children's Hospital and People's Hospital of Jinhua for sample collection.

\section{Funding}

This project was supported by the National Natural Science Foundation of China (NSFC) (81671487).

\section{Contributions}

Patient selection: P. Z and Y.Y; sample collection and processing: J. X, Q.Z and L.Y; data analysis and interpretation: P. Z and Q.Y; study design: C.F, L.Z and M.J; manuscript drafting: P. $Z$ and M.J. All authors read and approved the final manuscript.

\section{CONFLICT OF INTEREST}

The authors declare that there is no conflict of interest regarding the publication of this article.

\section{Ethics declarations}

\section{Ethics approval and consent to participate}

All trials were performed in strict accordance with the Ethics Committee at the Second Affiliated Hospital of Zhejiang University School of Medicine. Informed consent was exempt on account of retrospective study. The Committee of the Second Affiliated Hospital of Zhejiang University School of Medicine approved the protocols (registration number: 2021-0062).

\section{Consent for publication}

All co-authors have seen and approved the final version of the paper and have agreed to its submission for publication.

\section{Competing interests}

The authors declare that they have no competing interests.

\section{Availability of data and materials}

All data generated or analyzed during this study are included in this published article and its supplementary information files.

\section{References}

1. Lu Y, Yan J, Liu J, Tan J, Hong Y, Wei D, Chen Z, Sun Y. Prednisone for patients with recurrent implantation failure: study protocol for a double-blind, multicenter, randomized, placebo-controlled trial. Trials 2020; 21.

2. Ruiz-Alonso M, Blesa D, Díaz-Gimeno P, Gómez E, Fernández-Sánchez M, Carranza F, Carrera J, Vilella F, Pellicer A, Simón C. The endometrial receptivity array for diagnosis and personalized embryo transfer as a treatment for patients with repeated implantation failure. Fertil Steril 2013; 100: 818-824.

3. Ruiz-Alonso M, Galindo N, Pellicer A, Simon C. What a difference two days make: "personalized" embryo transfer (pET) paradigm: A case report and pilot study. Hum Reprod 2014; 29: 1244-1247.

4. Simón C, Gómez C, Cabanillas S, Vladimirov I, Castillón G, Giles J, Boynukalin K, Findikli N, Bahçeci M, Ortega I, Vidal C, Funabiki M, Izquierdo A, López L, Portela S, Frantz N, Kulmann M, Taguchi S, Labarta E, Colucci F, Mackens S, Santamaría X, Muñoz E, Barrera S, GarcíaVelasco JA, Fernández M, Ferrando M, Ruiz M, Mol BW, Valbuena D. A 5-year multicentre randomized controlled trial comparing personalized, frozen and fresh blastocyst transfer in IVF. Reprod Biomed Online 2020; 41: 402-415.

5. Immune therapies for women with history of failed implantation undergoing IVF treatment (Protocol).

6. Jones RL, Hannan NJ, Kaitu U TUJ, Zhang J, Salamonsen LA. Identification of Chemokines Important for Leukocyte Recruitment to the Human Endometrium at the Times of Embryo Implantation and Menstruation. The Journal of Clinical Endocrinology \& Metabolism 2004; 
89: 6155-6167.

7. Vissenberg R, Manders VD, Mastenbroek S, Fliers E, Afink GB, Ris-Stalpers C, Goddijn M, Bisschop PH. Pathophysiological aspects of thyroid hormone disorders/thyroid peroxidase autoantibodies and reproduction. Hum Reprod Update 2015; 21: 378-387.

8. Poppe K. Thyroid autoimmunity and hypothyroidism before and during pregnancy. Hum Reprod Update 2003; 9: $149-161$.

9. Sen A, Kushnir VA, Barad DH, Gleicher N. Endocrine autoimmune diseases and female infertility. Nature reviews. Endocrinology 2014; 10: 3750 .

10. van den Boogaard E, Vissenberg R, Land JA, van Wely M, van der Post JAM, Goddijn M, Bisschop PH. Significance of (sub)clinical thyroid dysfunction and thyroid autoimmunity before conception and in early pregnancy: a systematic review. Hum Reprod Update 2011; 17: 605619.

11. Bellver J, Soares SR, Alvarez C, Munoz E, Ramirez A, Rubio C, Serra V, Remohi J, Pellicer A. The role of thrombophilia and thyroid autoimmunity in unexplained infertility, implantation failure and recurrent spontaneous abortion. Hum Reprod 2007; 23: $278-284$.

12. Liu S, Xu F, Wei H, Huang C, Chen X, Lian R, Zeng Y. The correlation of thyroid autoimmunity and peripheral and uterine immune status in women with recurrent miscarriage. J Reprod Immunol 2020; 139: 103118.

13. Kilic S, Tasdemir N, Yilmaz N, Yuksel B, Gul A, Batioglu S. The effect of anti-thyroid antibodies on endometrial volume, embryo grade and IVF outcome. Gynecol Endocrinol 2008; 24: 649-655.

14. Litwicka K, Arrivi C, Varricchio MT, Mencacci C, Greco E. In women with thyroid autoimmunity, does low-dose prednisolone administration, compared with no adjuvant therapy, improvein vitro fertilization clinical results? J Obstet Gynaecol Re 2015; 41: $722-728$.

15. Revelli A, Dolfin E, Gennarelli G, Lantieri T, Massobrio M, Holte JG, Tur-Kaspa I. Low-dose acetylsalicylic acid plus prednisolone as an adjuvant treatment in IVF: a prospective, randomized study. Fertil Steril 2008; 90: 1685-1691.

16. Poppe K, Autin C, Veltri F, Sitoris G, Kleynen P, Praet J, Rozenberg S. Thyroid Disorders andln Vitro Outcomes of Assisted Reproductive Technology: An Unfortunate Combination? Thyroid 2020; 30: 1177-1185.

17. Toulis KA, Goulis DG, Venetis CA, Kolibianakis EM, Negro R, Tarlatzis BC, Papadimas I. Risk of spontaneous miscarriage in euthyroid women with thyroid autoimmunity undergoing IVF: a meta-analysis. Eur J Endocrinol 2010; 162: 643-652.

18. Alexander EK, Pearce EN, Brent GA, Brown RS, Chen H, Dosiou C, Grobman WA, Laurberg P, Lazarus JH, Mandel SJ, Peeters RP, Sullivan S. 2017 Guidelines of the American Thyroid Association for the Diagnosis and Management of Thyroid Disease During Pregnancy and the Postpartum. Thyroid 2017; 27: 315-389.

19. Wang H, Gao H, Chi H, Zeng L, Xiao W, Wang Y, Li R, Liu P, Wang C, Tian Q, Zhou Z, Yang J, Liu Y, Wei R, Mol BWJ, Hong T, Qiao J. Effect of Levothyroxine on Miscarriage Among Women With Normal Thyroid Function and Thyroid Autoimmunity Undergoing In Vitro Fertilization and Embryo Transfer. JAMA 2017; 318: 2190.

20. Dhillon-Smith RK, Middleton LJ, Sunner KK, Cheed V. Levothyroxine in Women with Thyroid Peroxidase Antibodies before Conception. N Engl J Med 2019; 380: 1316-1325.

21. Dosiou C. Thyroid and Fertility: Recent Advances. Thyroid 2020; 30: 479-486.

22. Wang X, Zhang Y, Tan H, Bai Y, Zhou L, Fang F, Faramand A, Chong W, Hai Y. Effect of levothyroxine on pregnancy outcomes in women with thyroid autoimmunity: a systematic review with meta-analysis of randomized controlled trials. Fertil Steril 2020; 114: 1306-1314.

23. Mor G, Aldo P, Alvero AB. The unique immunological and microbial aspects of pregnancy. Nat Rev Immunol $2017 ; 17: 469-482$.

24. Twig G, Shina A, Amital H, Shoenfeld Y. Pathogenesis of infertility and recurrent pregnancy loss in thyroid autoimmunity. J Autoimmun 2012; 38: J275-J281.

25. Wu Z, Cai Y, Xia Q, Liu T, Yang H, Wang F, Wang N, Yu Z, Yin C, Wang Q, Zhu D. Hashimoto's thyroiditis impairs embryo implantation by compromising endometrial morphology and receptivity markers in euthyroid mice. Reprod Biol Endocrin $2019 ; 17$.

26. Turi A, Giannubilo SR, Zanconi S, Mascetti A, Tranquilli AL. Preconception Steroid Treatment in Infertile Women with Antithyroid Autoimmunity Undergoing Ovarian Stimulation and Intrauterine Insemination: A Double-Blind, Randomized, Prospective Cohort Study. Clin Ther 2010; 32: 2415-2421.

27. Hasegawa I, Yamanoto Y, Suzuki M, Murakawa H, Kurabayashi T, Takakuwa K, Tanaka K. Prednisolone plus low-dose aspirin improves the implantation rate in women with autoimmune conditions who are undergoing in vitro fertilization. Fertil Steril 1998; 70: $1044-1048$.

28. Geva E, Amit A, Lerner-Geva L, Yaron Y, Daniel Y, Schwartz T, Azem F, Yovel I, Lessing JB. Prednisone and aspirin improve pregnancy rate in patients with reproductive failure and autoimmune antibodies: a prospective study. Am J Reprod Immunol 2000; 43: 36-40.

29. Quenby S, Farquharson R, Young M, Vince G. Successful pregnancy outcome following 19 consecutive miscarriages: case report. Hum Reprod 2003; 18: 2562-2564.

30. Ogasawara M, Aoki K. Successful uterine steroid therapy in a case with a history of ten miscarriages. Am J Reprod Immunol 2000; 44: 253255. 
31. Uppangala S, Daddangadi A, Joseph JS, Salian SR, Pandya RK, Kalthur G, Adiga SK. Stage-specific response in early mouse embryos exposed to prednisolone in vitro. J Endocrinol 2021; 248: 237-247.

32. Grbac E, So T, Varshney S, Williamson N, Dimitriadis E, Menkhorst E. Prednisolone Alters Endometrial Decidual Cells and Affects DecidualTrophoblast Interactions. Frontiers in Cell and Developmental Biology 2021; 9.

33. Evans MB, Nobles CJ, Kim K, Hill MJ, DeCherney AH, Silver RM, Mumford SL, Sjaarda LA, Perkins NJ, Schisterman EF. Low-dose aspirin in reproductive health: effects on menstrual cycle characteristics. Fertil Steril 2020; 114: 1263-1270.

34. Revelli A, Casano S, Piane LD, Grassi G, Gennarelli G, Guidetti D, Massobrio M. A retrospective study on IVF outcome in euthyroid patients with anti-thyroid antibodies: effects of levothyroxine, acetyl-salicylic acid and prednisolone adjuvant treatments. Reprod Biol Endocrinol 2009; 7: 137.

35. La Marca A, Nelson SM, Sighinolfi G, Manno M, Baraldi E, Roli L, Xella S, Marsella T, Tagliasacchi D, D Amico R, Volpe A. Anti-Müllerian hormone-based prediction model for a live birth in assisted reproduction. Reprod Biomed Online 2011; 22: $341-349$.

36. Te Velde ER, Pearson PL. The variability of female reproductive ageing. Hum Reprod Update 2002; 8: 141-154.

37. Rubio C, Gil-Salom M, Simón C, Vidal F, Rodrigo L, Mínguez Y, Remohí J, Pellicer A. Incidence of sperm chromosomal abnormalities in a risk population: relationship with sperm quality and ICSI outcome. Human reproduction (Oxford) 2001; 16: $2084-2092$.

38. Rubio C, Rodrigo L, Perez-Cano I, Mercader A, Mateu E, Buendia P, Remohi J, Simon C, Pellicer A. FISH screening of aneuploidies in preimplantation embryos to improve IVF outcome. Reprod Biomed Online 2005; 11: 497-506.

39. Gao M, Pang H, Zhao YH, Hua J, Tong D, Zhao H, Liu Y, Zhao Y, Zhang M, Yan XJ, Chen H, Ma HP, Jin TY, Dong SL. Karyotype analysis in large sample cases from Shenyang Women's and Children's hospital: a study of 16,294 male infertility patients. Andrologia 2017; 49: e12649.

40. Dong AC, Stephenson MD, Stagnaro-Green AS. The Need for Dynamic Clinical Guidelines: A Systematic Review of New Research Published After Release of the 2017 ATA Guidelines on Thyroid Disease During Pregnancy and the Postpartum. Front Endocrinol $2020 ; 11$.

41. Seungdamrong A, Steiner AZ, Gracia CR, Legro RS, Diamond MP, Coutifaris C, Schlaff WD, Casson P, Christman GM, Robinson RD, Huang H, Alvero R, Hansen KR, Jin S, Eisenberg E, Zhang H, Santoro N. Preconceptional antithyroid peroxidase antibodies, but not thyroid-stimulating hormone, are associated with decreased live birth rates in infertile women. Fertil Steril 2017; 108: 843-850.

42. Mitic D, Milenkovic JM, Milojkovic M, Jeremic M, Petric A, Basic M. Short-term dexamethasone plus acetylsalicylic acid treatment during in vitro fertilization procedure. Ginekol Pol 2019; 90: 201-205.

43. Dong AC, Morgan J, Kane M, Stagnaro-Green A, Stephenson MD. Subclinical hypothyroidism and thyroid autoimmunity in recurrent pregnancy loss: a systematic review and meta-analysis. Fertil Steril 2020; 113: 587-600.

44. Xie J, Jiang L, Sadhukhan A, Yang S, Yao Q, Zhou P, Rao J, Jin M. Effect of antithyroid antibodies on women with recurrent miscarriage: A meta-analysis. Am J Reprod Immunol 2020; 83.

45. Fan J, Zhong Y, Chen C. Combined treatment of prednisone and aspirin, starting before ovulation induction, may improve reproductive outcomes in ANA-positive patients. Am J Reprod Immunol 2016; 76: 391-395.

46. Ou H, Yu Q. Efficacy of aspirin, prednisone, and multivitamin triple therapy in treating unexplained recurrent spontaneous abortion: A cohort study. Int J Gynaecol Obstet 2020; 148: 21-26.

47. Sowi Ski J, Sawicka-Gutaj N, Gutaj P, Rucha A M. The role of free triiodothyronine in pathogenesis of infertility in levothyroxine-treated women with thyroid autoimmunity - a preliminary observational study. Gynecol Endocrinol 2015; 31: 116-118.

48. Aghajanova L, Stavreus-Evers A, Lindeberg M, Landgren B, Sparre LS, Hovatta O. Thyroid-stimulating hormone receptor and thyroid hormone receptors are involved in human endometrial physiology. Fertil Steril 2011; 95: 230-237.

49. Aghajanova L, Stavreus-Evers A, Lindeberg M, Landgren B, Sparre LS, Hovatta O. Thyroid-stimulating hormone receptor and thyroid hormone receptors are involved in human endometrial physiology. Fertil Steril 2011; 95: 230-237.

50. Salleh N, Sayem ASM, Giribabu N, Khaing SL. Expression of proteins related to thyroid hormone function in the uterus is down-regulated at the day of implantation in hypothyroid pregnant rats. Cell Biol Int 2019; 43: 486-494.

51. Young RE, Huh DD. Organ-on-a-chip technology for the study of the female reproductive system. Adv Drug Deliver Rev 2021; 173: 461-478.

52. Korevaar TIM, Pop VJ, Chaker L, Goddijn M, de Rijke YB, Bisschop PH, Broeren MA, Jaddoe VWV, Medici M, Visser TJ, Steegers EAP, Vrijkotte TG, Peeters RP. Dose Dependency and a Functional Cutoff for TPO-Antibody Positivity During Pregnancy. The Journal of Clinical Endocrinology \& Metabolism 2018; 103: 778-789.

\section{Tables}


Characteristics of women with positive antithyroid antibodies

\begin{tabular}{|c|c|c|c|c|c|c|}
\hline \multirow[t]{2}{*}{ Cycles } & \multicolumn{3}{|c|}{ Fresh embryo transfer cycles } & \multicolumn{3}{|c|}{ Frozen-thawed embryo transfer cycles } \\
\hline & control group $n=113$ & $P+A$ group $n=74$ & $P$ value & control group $n=83$ & $P+A$ group $n=76$ & $P$ value \\
\hline Age (yrs.) & $31.0(29.0-35.0)$ & $31.5(29.0-35.0)$ & 0.832 & $30.0(28.0-34.0)$ & $30.0(28.0-34.8)$ & 0.737 \\
\hline$<31$ & $44(38.9 \%)$ & $26(35.1 \%)$ & \multirow[t]{3}{*}{0.829} & $44(53.0 \%)$ & $39(51.3 \%)$ & \multirow[t]{3}{*}{0.727} \\
\hline $31-37$ & $63(55.8 \%)$ & $43(58.1 \%)$ & & $35(42.2 \%)$ & $31(40.8 \%)$ & \\
\hline$>37$ & $6(5.3 \%)$ & $5(6.8 \%)$ & & $4(4.8 \%)$ & $6(7.9 \%)$ & \\
\hline $\mathrm{BMI}\left(\mathrm{kg} / \mathrm{m}^{2}\right)$ & $22.0(20.0-24.0)$ & $22.3(20.2-25.1)$ & 0.336 & $22.38 \pm 2.97$ & $22.09 \pm 3.26$ & 0.557 \\
\hline $\mathrm{BMI} \geq 25\left(\mathrm{~kg} / \mathrm{m}^{2}\right)$ & $21(18.6 \%)$ & $21(28.4 \%)$ & 0.117 & 16(19.3\%) & $14(18.4 \%)$ & 0.890 \\
\hline Previous miscarriages & $0.0(0.0-1.0)$ & $1.0(0.0-1.0)$ & 0.636 & $0.0(0.0-1.0)$ & $0.0(0.0-1.0)$ & 0.752 \\
\hline$\geq 2$ & $21(18.6 \%)$ & $15(20.3 \%)$ & 0.775 & $7(8.4 \%)$ & $10(13.2 \%)$ & 0.336 \\
\hline Duration of infertility (yrs.) & $3.0(2.0-5.5)$ & $3.0(1.0-5.0)$ & 0.961 & $3.0(1.3-4.0)$ & $2.0(2.0-4.0)$ & 0.973 \\
\hline$<3$ & $53(46.9 \%)$ & $32(43.2 \%)$ & \multirow[t]{2}{*}{0.623} & $39(47.0 \%)$ & $40(52.6 \%)$ & \multirow[t]{2}{*}{0.477} \\
\hline$\geq 3$ & $60(53.1 \%)$ & $42(56.8 \%)$ & & $44(53.0 \%)$ & $36(47.4 \%)$ & \\
\hline Primary infertility & $50(44.2 \%)$ & $30(40.5 \%)$ & 0.616 & $42(50.6 \%)$ & $35(46.1 \%)$ & 0.566 \\
\hline Basal FSH(IU/L) & $5.74 \pm 1.57$ & $5.67 \pm 1.36$ & 0.732 & $6.2(4.7-7.1)$ & $5.2(4.4-6.3)$ & 0.094 \\
\hline AMH (ng/mL) & $2.7(1.7-3.7)$ & $2.9(1.9-4.2)$ & 0.429 & $4.3(2.4-6.5)$ & $3.9(1.9-6.0)$ & 0.327 \\
\hline AFC & $11.0(7.0-18.0)$ & $14(10.0-17.0)$ & 0.103 & $12.0(9.0-18.0)$ & $14.0(8.0-17.0)$ & 0.882 \\
\hline TSH (mlU/L) & $2.2(1.5-2.8)$ & $2.0(1.4-2.7)$ & 0.422 & $2.22 \pm 0.90$ & $1.99 \pm 0.86$ & 0.109 \\
\hline FT4 (ng/dL) & $1.00 \pm 0.14$ & $1.01 \pm 0.09$ & 0.475 & $1.0(0.9-1.1)$ & $1.0(1.0-1.1)$ & 0.867 \\
\hline FT3 $(p g / m L)$ & $3.05 \pm 0.44$ & $2.90 \pm 0.39$ & $0.017 \star$ & $2.99 \pm 0.48$ & $2.89 \pm 0.39$ & 0.145 \\
\hline Only TPOAb positivity & $9(8.0 \%)$ & $7(9.5 \%)$ & \multirow[t]{3}{*}{0.542} & $9(10.8 \%)$ & $12(15.8 \%)$ & \multirow[t]{3}{*}{0.592} \\
\hline Only TgAb positivity & $52(46.0 \%)$ & $28(37.8 \%)$ & & $33(39.8 \%)$ & $31(40.8 \%)$ & \\
\hline Both positivity & $52(46.0 \%)$ & $39(52.7 \%)$ & & $41(49.4 \%)$ & $33(43.4 \%)$ & \\
\hline \multicolumn{7}{|c|}{$P<0.05$ was considered to be statistically significant. * meant statistically significant difference between the two groups. } \\
\hline \multicolumn{7}{|c|}{$\begin{array}{l}\text { Continuous data were expressed as mean } \pm \text { SD when normally distributed, or as median (25th }-75 \text { th ) otherwise. Categorical variables were } \\
\text { expressed as number and percentage. }\end{array}$} \\
\hline
\end{tabular}


Table 2

Cycle characteristics and embryological data of studied groups

\begin{tabular}{|c|c|c|c|c|c|c|c|c|}
\hline \multirow[t]{2}{*}{ Cycles } & \multicolumn{4}{|c|}{ Fresh embryo transfer cycles } & \multicolumn{4}{|c|}{ Frozen-thawed embryo transfer cycles } \\
\hline & $\begin{array}{l}\text { control group } n \\
=113\end{array}$ & $\begin{array}{l}P+A \text { group } n \\
=74\end{array}$ & $\begin{array}{l}\mathrm{F} \\
\text { value }\end{array}$ & $\begin{array}{l}P \\
\text { value }\end{array}$ & $\begin{array}{l}\text { control group } n \\
=83\end{array}$ & $\begin{array}{l}P+A \text { group } n= \\
76\end{array}$ & $\begin{array}{l}\mathrm{F} \\
\text { value }\end{array}$ & $\begin{array}{l}\mathrm{P} \\
\text { value }\end{array}$ \\
\hline GnRHant/GnRHa & $28 / 85$ & $23 / 51$ & 0.895 & 0.344 & $38 / 45$ & $27 / 49$ & 1.727 & 0.189 \\
\hline Total Gn Dose (IU) & $\begin{array}{l}2250.0(1575.0- \\
2700.0)\end{array}$ & $\begin{array}{l}2250.0 \\
(1762.5- \\
2925.0)\end{array}$ & & 0.373 & $\begin{array}{l}1950.0(1425.0- \\
2550.0)\end{array}$ & $\begin{array}{l}1875.0(1425.0- \\
2225.0)\end{array}$ & & 0.437 \\
\hline Stimulation length (d) & $10.0(9.0-11.0)$ & $\begin{array}{l}10.0(9.0- \\
11.0)\end{array}$ & & 0.442 & $9.0(8.0-11.0)$ & $9.0(8.0-11.0)$ & & 0.897 \\
\hline $\begin{array}{l}\text { E2 level on HCG day } \\
(\mathrm{pg} / \mathrm{mL})\end{array}$ & $\begin{array}{l}2246.77 \pm \\
980.18\end{array}$ & $\begin{array}{l}2287.10 \pm \\
865.47\end{array}$ & & 0.547 & $\begin{array}{l}3449.1(2076.4- \\
4496.1)\end{array}$ & $\begin{array}{l}3811.1(2293.9- \\
5959.9)\end{array}$ & & 0.486 \\
\hline $\begin{array}{l}\text { Endometrial thickness on } \\
\text { hCG day }(\mathrm{mm})\end{array}$ & $12(10-12)$ & $12(10-12)$ & & 0.444 & / & / & & / \\
\hline Number of oocytes retrieved & $9.0(5.0-12.0)$ & $\begin{array}{l}10.0(6.0- \\
15.0)\end{array}$ & & 0.053 & $12.0(9.0-17.0)$ & $15.5(9.0-21.8)$ & & 0.057 \\
\hline IVF/ICSI & $102 / 11$ & $70 / 4$ & 1.136 & 0.287 & $70 / 13$ & $65 / 11$ & 0.044 & 0.834 \\
\hline Fertilization rate (\%) & $82.6(846 / 1024)$ & $80.4(634 / 789)$ & 1.521 & 0.217 & $81.0(856 / 1057)$ & 78.0(973/1247) & 3.056 & 0.080 \\
\hline Cleavage rate (\%) & $92.7(784 / 846)$ & 93.5(593/634) & 0.416 & 0.519 & $95.7(819 / 856)$ & 94.3(918/973) & 1.687 & 0.194 \\
\hline Available embryo rate (\%) & 61.2(480/784) & $56.2(333 / 593)$ & 3.588 & 0.058 & $56.8(465 / 819)$ & $55.4(509 / 918)$ & 0.311 & 0.577 \\
\hline \multicolumn{9}{|c|}{$P<0.05$ was considered to be statistically significant. } \\
\hline \multicolumn{9}{|c|}{$\begin{array}{l}\text { Continuous data were expressed as mean } \pm \text { SD when normally distributed, or as median (25th-75th) otherwise. Categorical variables were } \\
\text { expressed as number and percentage. }\end{array}$} \\
\hline
\end{tabular}


Table 3

Reproductive outcomes at the first embryo transfer and cumulative outcomes after 1-year follow-up

\begin{tabular}{|c|c|c|c|c|c|c|c|c|}
\hline \multirow[t]{2}{*}{ Cycles } & \multicolumn{4}{|c|}{ Fresh embryo transfer cycles } & \multicolumn{4}{|c|}{ Frozen-thawed embryo transfer cycles } \\
\hline & $\begin{array}{l}\text { control group } \\
n=113\end{array}$ & $\begin{array}{l}P+A \text { group } \\
n=74\end{array}$ & $\begin{array}{l}\mathrm{F} \\
\text { value }\end{array}$ & $\begin{array}{l}P \\
\text { value }\end{array}$ & $\begin{array}{l}\text { control group } \\
n=83\end{array}$ & $\begin{array}{l}P+A \text { group } \\
n=76\end{array}$ & $\begin{array}{l}\mathrm{F} \\
\text { value }\end{array}$ & $\begin{array}{l}\mathrm{P} \\
\text { value }\end{array}$ \\
\hline \multicolumn{9}{|l|}{ Embryo stage, n (\%) } \\
\hline Cleavage stage & 108(95.6\%) & 72(97.3\%) & \multirow[t]{2}{*}{0.368} & \multirow[t]{2}{*}{0.544} & 73(88.0\%) & $71(93.4 \%)$ & \multirow[t]{2}{*}{1.389} & \multirow[t]{2}{*}{0.239} \\
\hline Blastocyst stage & $5(4.4 \%)$ & $2(2.7 \%)$ & & & $10(12.0 \%)$ & $5(6.6 \%)$ & & \\
\hline Number of embryos transferred & $1.88 \pm 0.33$ & $1.93 \pm 0.25$ & & 0.214 & $1.81 \pm 0.40$ & $1.84 \pm 0.37$ & & 0.565 \\
\hline $\begin{array}{l}\text { Endometrial thickness on embryo } \\
\text { transfer day }(\mathrm{mm})\end{array}$ & / & / & & / & $9.1(8.5,11.0)$ & $9.1(8.5,11.0)$ & & 0.984 \\
\hline Implantation rate (\%) & $40.1(85 / 212)$ & $44.8(64 / 143)$ & 0.762 & 0.355 & $42.0(63 / 150)$ & $46.4(65 / 140)$ & 0.576 & 0.448 \\
\hline $\begin{array}{l}\text { Implantation rate of cleavage stage } \\
\text { embryos (\%) }\end{array}$ & $40.2(82 / 204)$ & $44.7(63 / 141)$ & 0.688 & 0.407 & $39.7(54 / 136)$ & $45.5(60 / 132)$ & 0.906 & 0.341 \\
\hline $\begin{array}{l}\text { Implantation rate of blastocyst } \\
\text { stage embryos (\%) }\end{array}$ & $37.5(3 / 8)$ & $50.0(1 / 2)$ & / & / & $60.0(9 / 14)$ & $62.5(5 / 8)$ & / & / \\
\hline Pregnancy rate (\%) & 63.7(72/113) & $64.9(48 / 74)$ & 0.026 & 0.873 & $65.1(54 / 83)$ & $65.8(50 / 76)$ & 0.009 & 0.923 \\
\hline Clinical pregnancy rate (\%) & $57.5(65 / 113)$ & $63.5(47 / 74)$ & 0.668 & 0.414 & $57.8(48 / 83)$ & $61.8(47 / 76)$ & 0.265 & 0.606 \\
\hline Miscarriage rate (\%) & $13.8(9 / 65)$ & $25.5(12 / 47)$ & 2.445 & 0.118 & $18.8(9 / 48)$ & $27.7(13 / 47)$ & 1.059 & 0.303 \\
\hline Neonatal mortality rate (\%) & $0(0 / 113)$ & $0(0 / 74)$ & & & $0(0 / 83)$ & $0(0 / 76)$ & & \\
\hline Live birth rate (\%) & $49.6(56 / 113)$ & $47.3(35 / 74)$ & 0.091 & 0.762 & $47.0(39 / 83)$ & $44.7(34 / 76)$ & 0.081 & 0.776 \\
\hline Total additional transfers, $\mathrm{n}$ & 17 & 26 & & & 11 & 10 & & \\
\hline Cumulative transfers, $\mathrm{n}$ & 130 & 100 & & & 94 & 86 & & \\
\hline Cumulative pregnancy rate (\%) & $64.6(84 / 130)$ & $63.0(63 / 100)$ & 0.064 & 0.800 & $63.8(60 / 94)$ & $67.4(58 / 86)$ & 0.260 & 0.610 \\
\hline $\begin{array}{l}\text { Cumulative clinical pregnancy rate } \\
(\%)\end{array}$ & $56.9(74 / 130)$ & $61.0(61 / 100)$ & 0.388 & 0.534 & $55.3(52 / 94)$ & $60.5(52 / 86)$ & 0.488 & 0.485 \\
\hline Cumulative implantation rate (\%) & $40.3(98 / 243)$ & $42.9(82 / 191)$ & 0.298 & 0.585 & $40.4(67 / 166)$ & $45.8(71 / 155)$ & 0.970 & 0.325 \\
\hline $\begin{array}{l}\text { Cumulative implantation rate of } \\
\text { cleavage stage embryos (\%) }\end{array}$ & $40.5(90 / 222)$ & $43.0(71 / 165)$ & 0.242 & 0.623 & $38.5(55 / 143)$ & $45.5(60 / 132)$ & 1.380 & 0.240 \\
\hline $\begin{array}{l}\text { Cumulative implantation rate of } \\
\text { blastocyst stage embryos (\%) }\end{array}$ & $38.1(8 / 21)$ & $42.3(11 / 26)$ & 0.086 & 0.770 & $52.2(12 / 23)$ & $47.8(11 / 23)$ & 0.087 & 0.768 \\
\hline Cumulative live birth rate (\%) & $47.7(62 / 130)$ & $46.0(46 / 100)$ & 0.065 & 0.799 & $45.7(43 / 94)$ & $43.0(37 / 86)$ & 0.135 & 0.714 \\
\hline \multicolumn{9}{|c|}{$P<0.05$ was considered to be statistically significant. } \\
\hline
\end{tabular}


Table 4

Multivariable logistic regression analysis.

\begin{tabular}{|c|c|c|c|c|c|c|c|c|}
\hline \multirow{3}{*}{$\begin{array}{l}\text { Dependent outcomes } \\
\text { Independent variables }\end{array}$} & \multicolumn{4}{|c|}{ Fresh embryo transfer cycles } & \multicolumn{4}{|c|}{ Frozen-thawed embryo transfer cycles } \\
\hline & \multicolumn{2}{|c|}{ Miscarriage rate } & \multicolumn{2}{|c|}{ Clinical pregnancy rate } & \multicolumn{2}{|c|}{ Miscarriage rate } & \multicolumn{2}{|c|}{ Clinical pregnancy rate } \\
\hline & $\mathrm{aOR}[\mathrm{Cl}]$ & $P$ & $\mathrm{aOR}[\mathrm{Cl}]$ & $\mathrm{P}$ & $\mathrm{aOR}[\mathrm{Cl}]$ & $\mathrm{P}$ & $\mathrm{aOR}[\mathrm{Cl}]$ & $\mathrm{P}$ \\
\hline Age(yrs.) & $\begin{array}{l}0.983[0.850- \\
1.135]\end{array}$ & 0.812 & $\begin{array}{l}1.040[0.957- \\
1.130]\end{array}$ & 0.352 & $\begin{array}{l}1.002[0.886- \\
1.133]\end{array}$ & 0.975 & $\begin{array}{l}0.971[0.895- \\
1.054]\end{array}$ & 0.486 \\
\hline FT3(pg/mL) & $\begin{array}{l}0.248[0.063- \\
0.984]\end{array}$ & $0.047 *$ & $\begin{array}{l}1.323[0.651- \\
2.690]\end{array}$ & 0.439 & & & & \\
\hline $\mathrm{P}+\mathrm{A}$ treatment & $\begin{array}{l}0.548[0.204- \\
1.468]\end{array}$ & 0.232 & $\begin{array}{l}0.748[0.404- \\
1.382]\end{array}$ & 0.353 & $\begin{array}{l}0.603[0.229- \\
1.587]\end{array}$ & 0.306 & $\begin{array}{l}0.839[0.443- \\
1.586]\end{array}$ & 0.588 \\
\hline
\end{tabular}

\section{Supplemental Table}

Supplemental Table SV is not available with this version.

\section{Figures}




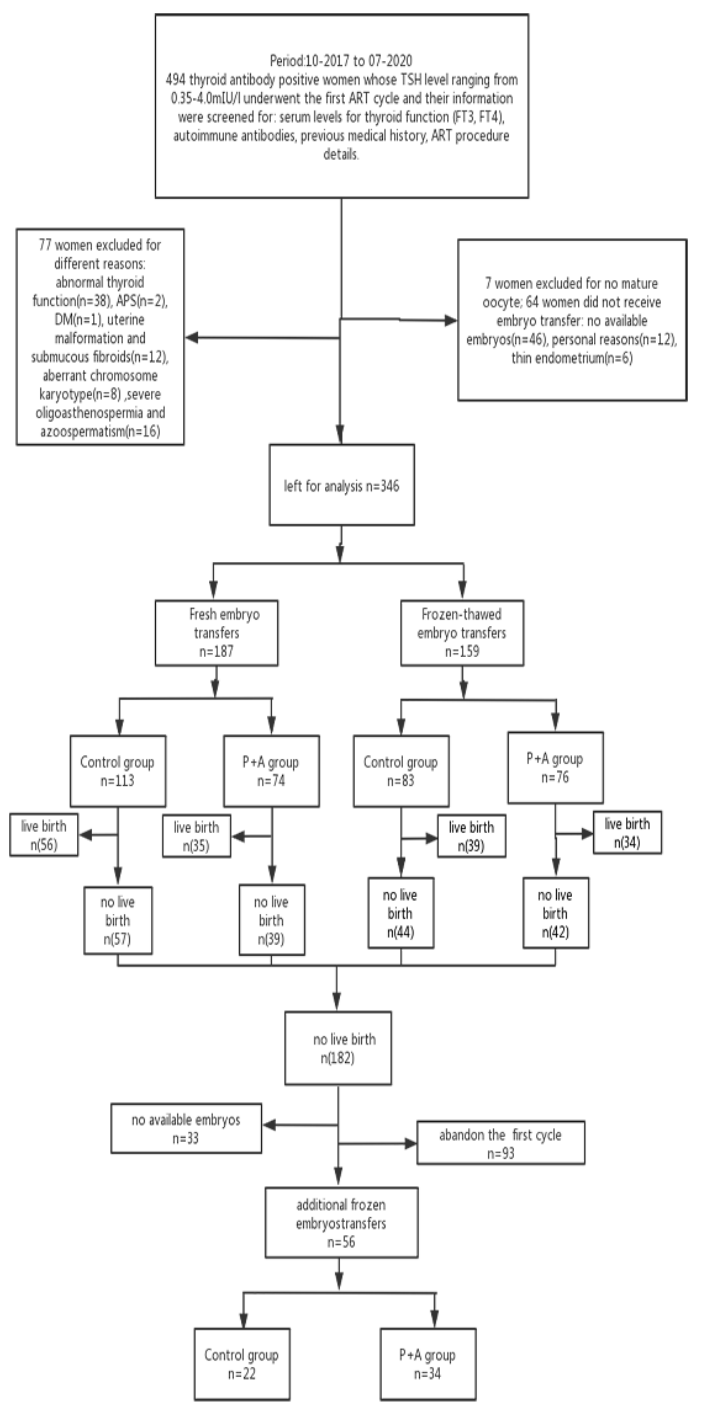

Figure 1

Flowchart illustrating the selection of the infertile women and their grouping and IVF outcomes

\section{Supplementary Files}

This is a list of supplementary files associated with this preprint. Click to download.

- SUPPLEMENT.docx 